\title{
Assessment of Nutritional Status and Its Determinants Among Pre-School Children Within Dalit Communities of Jessore City in Bangladesh: A Cross-Sectional Study
}

\author{
Akimul Islam, Md Tarek Hasan, Nazia Nawshad Lina, Fatema-Tuj-Johra, Shovon Al-Fuad, \\ Rajib Kanti Roy*
}

Department of Nutrition and Food Technology, Jessore University of Science and Technology, Jessore, Bangladesh

Email address:

rajib131kushtia@gmail.com(R.K. Roy)

${ }^{*}$ Corresponding author

\section{To cite this article:}

Akimul Islam, Md Tarek Hasan, Nazia Nawshad Lina, Fatema-Tuj-Johra, Shovon Al-Fuad, Rajib Kanti Roy. Assessment of Nutritional Status and Its Determinants Among Pre-School Children Within Dalit Communities of Jessore City in Bangladesh: A Cross-Sectional Study. International Journal of Nutrition and Food Sciences. Vol. 7, No. 2, 2018, pp. 65-70. doi: 10.11648/j.ijnfs.20180702.14

Received: February 3, 2018; Accepted: March 8, 2018; Published: March 24, 2018

\begin{abstract}
Background: The socio-religiously considered low class Dalit communities are living below extreme poverty line in Bangladesh. They face discrimination at all levels of social interactions. Lack of access to education, extreme poverty issues, health and housing problems, and unequal access to work and employment may put this underprivileged community at the risk of malnutrition. Objectives: This study was carried out to determine the nutritional status and associated factors among preschool children within various Dalit communities in Jessore city, Bangladesh. Study Design: A cross sectional study was undertaken among 165 pre-school children (24-60 months) randomly selected from different Dalit families living in Jessore city, Bangladesh. Anthropometric methods and a structured questionnaire were used to collect the required data. WHO based anthropometric Z scores and MUAC (Mid Upper Arm Circumference) indicators were used to measure nutritional status of the children. Data analysis at 5\% level of significance was performed by Statistical Package for Social Science (SPSS)-22 software. Results: About $58 \%$ and $45 \%$ of the studied preschool children were stunted and underweight respectively while $22.5 \%$ children were wasted. Nearly $8.5 \%$ children were obese or at risk of being obese. Most of the parents were illiterate or just completed only primary education. Mother and father education status was not statistically significant with stunting, wasting and underweight status of pre-school children. Moderate and severe stunting were relatively higher among younger children ( $\mathrm{p}<0.05$ ). According to MUAC assessment $82.4 \%$ of the children were normal, $16.9 \%$ had mild to moderate and $0.6 \%$ was severely malnourished. Most of those malnourished children belonged to younger age groups $(p<0.01)$. MUAC of the children was significant with their mother education status $(p<0.05) .61 .2 \%$ children who suffered diarrhea or pneumonia in last 2 months had lower weight for age $(p<0.05)$ and weight for height $(\mathrm{p}<0.01)$ than who didn't. Conclusions: About half of preschool children among Dalit communities in Jessore city live with chronic malnutrition like stunting and underweight. Maternal health status as well as other socio-demographic factors can affect the nutritional status of children.
\end{abstract}

Keywords: Nutritional Status, Preschool Children, Dalit Community, Socio-Demographic

\section{Introduction}

Child malnutrition is considered as one of the major public health problems in developing countries like Bangladesh where resources are highly insufficient. Adequate nutrition is believed to be key factor for a country's socio economic development. Malnourished people are reflected as burden for a nation [1]. Malnutrition is subdivided into under- nutrition and over-nutrition. Under-nutrition is much more prevalent than over-nutrition in Bangladesh. Millions of children and women suffer from one or more forms of malnutrition, including low birth weight, underweight, wasting, stunting, and micronutrient deficiency [2]. According to WHO (1998), in South Asia, 17\% under fiveyear children were wasted and $60 \%$ were stunted. 160 million children were underweight in which up to $50 \%$ being in 
South Asia [3]. Present health and nutritional status of children is a reflection of their past health practices and nutritional behaviors, again, which are largely influenced by their existing associated socio-demographic status. Children with a poor socio-economic and nutrition condition are highly likely to be malnourished mothers, who further to some extent can viciously impact the nutritional status of their future children. Therefore, the nutritional status of children in a society can highly reflect its wholesomeness [4]. Under 5 years children are generally considered as nutritionally vulnerable. Physical and mental health developments occur very quickly in these early years of life, which requires provision of balanced nutrition and confirmation of other health and socio-demographic privileges. If these crucial nutritional and health requirements of these children at this early age are not guaranteed, they can suffer moderate to severe growth retardation which has been found to be associated with increased morbidity, mortality, and decreased cognitive performance in their later phase of life [5]. Extreme poverty, inadequate nutritional knowledge, poor health and sanitary conditions among households, and low incomes are considered as the primary reasons for the high prevalence of child malnutrition [6,7]. Sufficient food production is directly associated with improved nutrition while monetary abundance is a perquisite for sufficient food production [7, 8]. "Dalit" is a socio-religious excluded community often considered as "untouchable" in the societies they live in different regions of South Asia. People of this community are deprived, partly by religious sanctions and partly by socio-economic discrimination. They include cobbler, barber, sweeper, garland maker, potter, fisherman, honey collector etc. [9]. There are approximately 5.5 to 6.5 million Dalit people live in Bangladesh [10]. Dalit people live under the poverty line, they have extremely limited privilege of education, health service, safe housing and employment [11]. Mainly, they live in various filthy and congested urban slums and usually they are found to depend on scavenging, street sweeping and dead body burying etc. for their livelihood, which are usually often considered as unpleasant works to the remaining society. There might be a high risk of Dalit children are being subjected to more deprivation and discrimination in terms of various important social privileges like health and education which may make them more nutritionally vulnerable than their non-Dalit counterparts [12].

Let alone determining any specific nutritional status of Dalit children, very few social studies were conducted on Dalit people to assess their present socio-demographic status in Bangladesh. Although some studies were conducted on nutritional status of Dalit preschool children in India, Nepal, Bhutan and Pakistan, there is no known such single research yet done in perspective of Bangladesh [13, 14]. Therefore, this study was carried out to assess nutritional status and its determinants among pre-school children within Dalit communities in Jessore city, Bangladesh.

\section{Methodology}

A descriptive type of cross sectional study was carried out among preschool children of Dalit communities living in four regions of Jessore city namely Churamonkathi, Doratana, Dharmotola and Chacra. Total 165 pre-school children aged between 24 to 60 months were studied. Standardized salter and seca weighing scales were used to measure weight $(\mathrm{kg})$ of the children. Height measuring tape and height boards were used for their height $(\mathrm{cm})$ measurement. MUAC $(\mathrm{cm})$ was measured by a non-stretchable and flexible plastic tape. A necessary training was given to data collectors before starting the survey to minimize inter rater variability. Data were checked randomly in the field to measure its reliability and preciseness.

A pre-coded questionnaire was used for the survey to obtain information about nutritional status and its determinants among pre-school children. The questionnaire consisted of three parts as socioeconomic, demographic and anthropometric measurement. It was tested among 20 children in Ambottola village and some corrections of data were done based on findings. The objective of the study was informed to the household member and oral permission was wanted before data collection. Ethical approval was taken from Jessore University of Science and Technology Review Committee.

Wasting, stunting and underweight were measured as Weight-for-height, height-for-age and weight-for-age of the studied children. Using WHO-anthro software (3.2.2 version) $\mathrm{Z}$ scores for Weight-for-height, height-for-age and weightfor-age were calculated and classified according to WHO reference criteria $[15,16]$.

Weight for height $\mathrm{z}$ scores (WHZ) below -2SD indicates moderate thinness among subjects which is considered as recent nutritional deficiency caused by foods unavailability and recent incidence of any infectious disease. Wasting or thinness is acute measurement of malnutrition. Similarly, height-for-age $\mathrm{z}$ scores (HAZ) and weight for age scores WAZ below -2SD present children as moderately stunted and underweight. Stunting is a chronic form of nutritional status resulting from inadequate dietary intake and frequent morbidity for extended periods whereas weight-for-age $\mathrm{z}$ scores (WAZ) is a combination of weight-for-height and height-for-age, therefore simultaneously can indicate the presence of both acute and chronic malnutrition. Any $\mathrm{Z}$ scores below -3SD indicated severe form of malnutrition. SPSS version-22 software was used to analyze required statistical analyses at 5\% level of significance.

\section{Results}

Table 1. Distribution of children by their age and sex $(n=165)$.

\begin{tabular}{llll}
\hline Characteristics & & Number & Percentage (\%) \\
\hline \multirow{3}{*}{ Age Group (months) } & $24-35$ & 43 & 26.1 \\
& $36-47$ & 38 & 23.0 \\
\multirow{2}{*}{ Sex } & $48-60$ & 84 & 50.9 \\
& Male & 76 & 46.1 \\
& Female & 89 & 53.9 \\
\hline
\end{tabular}


Table 2. Distribution of children by selected socio-demographic characteristics $(n=165)$.

\begin{tabular}{llll}
\hline Characteristics & & Number & Percentage (\%) \\
\hline \multirow{4}{*}{ Fathers' education } & Illiterate & 46 & 27.9 \\
& Primary & 92 & 55.8 \\
& High school & 20 & 12.1 \\
& Above SSC & 7 & 4.2 \\
\multirow{4}{*}{ Mothers' education } & Illiterate & 32 & 19.4 \\
& Primary & 82 & 49.7 \\
& High school & 44 & 26.7 \\
& Above SSC & 7 & 4.2 \\
Fathers' occupation & Unemployed & 2 & 1.2 \\
& Sweeper & 53 & 32.1 \\
& Cobbler & 20 & 12.1 \\
\hline
\end{tabular}

\begin{tabular}{llll}
\hline Characteristics & & Number & Percentage (\%) \\
\hline & Barber & 15 & 9.1 \\
& Others & 75 & 45.5 \\
Monthly family income & $\leq 5000$ & 76 & 46.1 \\
(BDT) & $5001-10000$ & 60 & 36.4 \\
& $10001-15000$ & 24 & 14.5 \\
\hline
\end{tabular}

It was found that as high as $19.4 \%$ mother was illiterate whereas only $4.2 \%$ mother was educated above SSC level. $32.1 \%$ father earned their livelihood by sweeping, $12.1 \%$ father were cobbler, $9.1 \%$ were barber, about $45.5 \%$ did others job and only $1.2 \%$ were unemployed.

Table 3. Distribution of nutritional status of the children by weight-for-age, height-for-age and weight-for-height Z-score.

\begin{tabular}{|c|c|c|c|c|c|}
\hline Indices & $<-3.00$ SD & -3.00 SD to -2.01 SD & -2.00 SD to 1.01 SD & \pm 1 SD & +2.00 SD to +1.01 SD \\
\hline Weight for age (underweight) & $1(0.6 \%)$ & $15(9.1 \%)$ & $58(35.2 \%)$ & $82(49.7 \%)$ & $9(5.5 \%)$ \\
\hline Height for age (stunting) & $16(9.7 \%)$ & $32(19.4 \%)$ & $48(29.1 \%)$ & $59(35.8 \%)$ & $10(6.1 \%)$ \\
\hline Weight for height (wasting) & 0 & $10(6.1 \%)$ & $27(16.4 \%)$ & $114(69.0 \%)$ & $14(8.5 \%)$ \\
\hline
\end{tabular}

Note: Severe malnutrition=<-3.00 SD, Moderate malnutrition=-3.00 SD to $-2.01 \mathrm{SD}$, Mild malnutrition=-2.00 SD to $1.01 \mathrm{SD}$, Normal $= \pm 1$ SD, Over nutrition $=+2.00 \mathrm{SD}$ to $+1.01 \mathrm{SD}$.

Table 4. Association of the selected socio-demographic variables with different under-nutrition indicators.

\begin{tabular}{llll}
\hline Variables & Weight for age (underweight) & Height for age (stunting) & Weight for height (wasting) \\
\hline Child sex & $\mathrm{X}^{2}=2.87, \mathrm{P}>0.05$ & $\mathrm{X}^{2}=3.65, \mathrm{P}>0.05$ & $\mathrm{X}^{2}=8.80, \mathrm{P}>0.05$ \\
Child Age & $\mathrm{X}^{2}=7.94, \mathrm{P}>0.05$ & $\mathrm{X}^{2}=25.00, \mathrm{P}<0.05^{*}$ & $\mathrm{X}^{2}=7.60, \mathrm{P}>0.05$ \\
Number of family members & $\mathrm{X}^{2}=4.56, \mathrm{P}>0.05$ & $\mathrm{X}^{2}=20.24, \mathrm{P}<0.05^{*}$ & $\mathrm{X}^{2}=5.19, \mathrm{P}>0.05$ \\
Mothers' BMI & $\mathrm{X}^{2}=18.64, \mathrm{P}<0.05^{*}$ & $\mathrm{X}^{2}=12.60, \mathrm{P}<0.05^{*}$ & $\mathrm{X}^{2}=18.38, \mathrm{P}>0.05$ \\
Monthly family income & $\mathrm{X}^{2}=11.62, \mathrm{P}>0.05$ & $\mathrm{X}^{2}=17.15, \mathrm{P}>0.05$ & $\mathrm{X}^{2}=14.76, \mathrm{P}>0.05$ \\
Father's education level & $\mathrm{X}^{2}=16.31, \mathrm{P}>0.05$ & $\mathrm{X}^{2}=17.15, \mathrm{P}>0.05$ & $\mathrm{X}^{2}=19.59, \mathrm{P}>0.05$ \\
Mother's education level & $\mathrm{X}^{2}=11.13, \mathrm{P}>0.05$ & $\mathrm{X}^{2}=13.55, \mathrm{P}>0.05$ & $\mathrm{X}^{2}=16.93, \mathrm{P}>0.05$ \\
Mother's age & $\mathrm{X}^{2}=41.79, \mathrm{P}<0.05^{*}$ & $\mathrm{X}^{2}=40.40, \mathrm{P}<0.05^{*}$ & $\mathrm{X}^{2}=20.00, \mathrm{P}>0.05$ \\
\hline
\end{tabular}

Note: level of significance was $5 \%$ and $\chi 2$ test was performed. Single asterisk $(*)$ indicates a statistically significant relationship.

Table 4 represented that child age, number of family members, mother's BMI and mother's age had significant relationship with nutritional status of children.

Table 5. The distribution of mean WAZ score and WHZ score among children by the incidences of diarrhea \& pneumonia disease in last two months ( $n=165$ ).

\begin{tabular}{|c|c|c|c|c|c|}
\hline Diarrhea \& Pneumonia & Number of children (\%) & Mean $( \pm$ SD) V & & Mean ( \pm SD) & ore \\
\hline $\begin{array}{l}\text { Yes } \\
\text { No }\end{array}$ & $\begin{array}{l}101(61.2 \%) \\
64(38.78 \%)\end{array}$ & $\begin{array}{l}-0.83 \pm(0.98) \\
-0.47 \pm(1.07)\end{array}$ & $P<0.05^{*}$ & $\begin{array}{l}-0.16( \pm 1.32) \\
0.40( \pm 1.39)\end{array}$ & $P<0.05^{*}$ \\
\hline
\end{tabular}

Single asterisk (*) indicates a statistically significant relationship at 5\% level of significance.

Table 5 shows among children who suffered diarrhea or pneumonia in last 2 months had lower weight for age and weight for height than who didn't suffer.

Table 6. Gender based distribution of children by different categories of MUAC.

\begin{tabular}{|c|c|c|c|c|c|c|}
\hline \multirow{2}{*}{ MUAC (cm) } & \multirow{2}{*}{ Nutritional status } & \multicolumn{2}{|l|}{ Gender } & \multirow{2}{*}{ Total } & \multirow{2}{*}{$\chi^{2}$} & \multirow[b]{2}{*}{$p$} \\
\hline & & Male & Female & & & \\
\hline$\geq 14.5$ & Normal & $60(44.1 \%)$ & $76(55.9 \%)$ & $136(82.4 \%)$ & \multirow{4}{*}{2.37} & \multirow{4}{*}{.50} \\
\hline $13.5-14.4$ & Mild malnutrition & $10(50.0 \%)$ & $10(50.0 \%)$ & $20(12.1 \%)$ & & \\
\hline $12.5-13.4$ & Moderate malnutrition & $5(62.5 \%)$ & $3(37.5 \%)$ & $8(4.8 \%)$ & & \\
\hline$<12.5$ & Severe malnutrition & $1(100.0 \%)$ & $0(0.0 \%)$ & $1(0.6 \%)$ & & \\
\hline
\end{tabular}

Results were published as number (\%), level of significance was $5 \%$, and $\chi^{2}$ test was performed.

Table 6 presented, $82.4 \%$ children were normal whereas $12.1 \%, 4.8 \%$, and $0.6 \%$ children were mild, moderate and severely malnourished respectively according to MUAC assessment. Male children were comparatively more moderately malnourished than female children. 
Table 7. Association of the selected socio-demographic variables with MUAC of the children.

\begin{tabular}{ll}
\hline Selected variables & MUAC of the children \\
\hline Children Sex & $\mathrm{X}^{2}=2.37, \mathrm{P}>0.05$ \\
Children Age & $\mathrm{X}^{2}=24.14, \mathrm{P}<0.05^{*}$ \\
Mother's education & $\mathrm{X}^{2}=24.87, \mathrm{P}<0.05^{*}$ \\
Children's diarrhea and pneumonia (in last 2 months) & $\mathrm{X}^{2}=7.91, \mathrm{P}<0.05^{*}$ \\
\hline
\end{tabular}

Single asterisk $(*)$ indicates a statistically significant relationship at $5 \%$ level of significance.

Table 7 presented that MUAC of the children was significantly associated with children age, their suffering from diarrhea and pneumonia in last two months and mother's education.

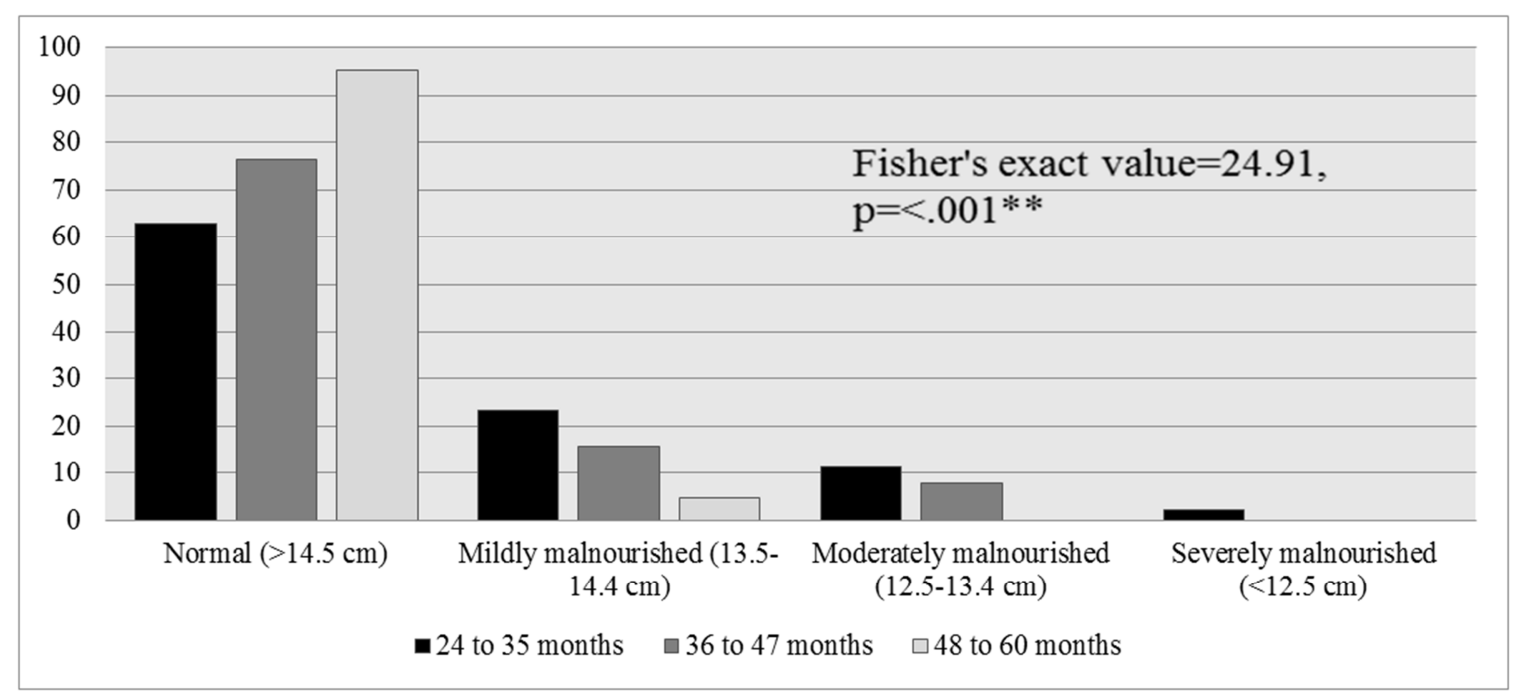

Double asterisks $(* *)$ indicates a statistically highly significant relationship between children age group and nutritional status based on MUAC indicator

Figure 1. Distribution of children age groups by different categories of nutritional status based on MUAC indicators.

Figure 1 reveals that each category of malnourishment based on MUAC indicator was siginificatly higher among children of younger age groups $(\mathrm{p}=<.001)$. With the increase of age groups there was an increase of number of children with normal MUAC level while with the increase of age groups there was a decrease of children with mild, moderate and severe malnutrtion based on level of MUAC indicator.

\section{Discussion}

About $58 \%$ and $45 \%$ of the studied preschool children were stunted and underweight respectively while $22.5 \%$ children were suffering acute malnutrition. According to Bangladesh Demographic and Health Survey 2014, among preschool children, prevalence of stunting was $36 \%$, wasting was $14 \%$ and underweight was $33 \%$ [17]. This study revealed that preschool children of Dalit communities in Jessore city were more affected from stunting or chronic malnutrition, wasting and underweight when compared to the national figure of child malnutrition. Higher rate of prevailing malnutrition and extensive growth retardation among these Dalit children can explain this discrepancy. Relatively poor nutrition may be due to living below extreme poverty line, limited access to health facilities, better education and employment opportunities, and other prevailing sociodemographic discrepancies among this underprivileged social group which often is isolated as low caste people in the society [18]. A cross sectional study by using 55 low and middle-income countries demographic health data found that first child aged from 12 to 60 months of mothers aged less than 27 years had greater risk for infant mortality and underweight, stunting, diarrhea among children [19]. The current study also showed a significant relation between maternal age and nutritional status of their preschool children. Unemployment, low paid jobs, illiteracy can cause food insecurity and inadequate health care. Adequate money is needed to afford nutritious food for family. Due to money shortage households that cannot purchase sufficient nutritious food are mostly deprived of balance diet and suffered from disease that ultimately results in malnutrition [20]. In a comparative study done more than 15 countries represented a decreasing trend of stunting, wasting and underweight with increasing household income [21]. Similarly, this study also found a significant relationship between nutrition status of preschool children with their monthly household income. A study carried out in Raja Rammohunpur, West Bengal 734 013, India found a highly significant correlation between mothers BMI with children's BMIZ and HAZ [22]. This present study also replicated similar significant correlation between mothers BMI and children's nutritional status. Other several factors such as children age, level of mother's education, and occurrence of diseases like pneumonia and 
diarrhea among preschool children in the last two months had significant impact on children's MUAC status. A study on effect of maternal education on preschool children's nutritional status in nearby India showed that children of educated mothers had improved health status than that of uneducated mothers' [23]. Incompatible with those previous studies, this study indicated that mother and father education status was insignificant with the observed malnutrition status of pre-children. Incidence of diseases affects both dietary intake and absorption of nutrients among children thereby having a negative impact on the betterment of their health and nutritional status. A similar study revealed that more children were underweight those who had gone through diarrhea in their last month [24]. The present study also noticed that children who suffered diarrhea or pneumonia in last 2 months had lower weight for age $\mathrm{Z}$ score (WAZ) and weight for height (WHZ) than who didn't suffer. MUAC of the children was significantly associated with their age, their suffering from diarrhea and pneumonia in last two months and their mother's education. According to MUAC assessment, $82.4 \%$ children were normal whereas $12.1 \%$, $4.8 \%$, and $0.6 \%$ children were mild, moderate and severely malnourished respectively. Male children were comparatively more moderately malnourished than female children. Severity of malnutrition was decreased among children of older age groups. To the contrary, a similar study on preschool children of three districts showed $35 \%$ of children were normal whereas $38 \%, 14.5 \%$ and $12.5 \%$ children were mild, moderate and severely malnourished [25].

\section{Conclusions}

The overall nutritional status of the pre-school children of socio-economically deprived Dalit communities in Jessore city was worse than that of nutritional status at national level in Bangladesh. About half of preschool children among Dalit communities in Jessore city are living with chronic malnutrition like stunting and underweight. Remarkably, socio-demographic variables like maternal age, monthly household income, mothers BMI, incidence of infectious diseases impacted the nutritional wellbeing of the children of this vulnerable group of population.

Therefore, for betterment of prevailing nutritional status of Dalit children realistic interventions like creating adequate employment opportunity and providing better education among Dalit population are recommended by government besides raising required awareness to improve their health and nutritional knowledge through nutritional campaign on a regular basis.

\section{References}

[1] Chataut, J., Khanal, K. 2016 Assessment of nutritional status of children under five years of age in rural Nepal, Kathmandu Univ Med J.; 53 (1):73-7.

[2] United Nations Children's Fund, "The State of the World's
Children 2007. Women and Children: The Double Dividend of Gender Equality," 2007.

[3] The World Health Report 1998: life in the $21^{\text {st }}$ century. (1998).

[4] Gitau R, Makasa M, Kasonka L, Sinkala M, Chintu C, Tomkins A, Filteau S, 2005, Maternal micronutrient status and decreased growth of Zambian infants born during and after the maize price increases resulting from the southern African drought of 2001-2002. Public Health Nutr.; 8:837-43.

[5] Garrows, J. S., Human nutrition dietatics, Chapter 2; 1987, pp 13-15.

[6] Anderson, per-pinstrup. Nutritional consideration into Agricultural and Rural Development, International Food Policy Research Institute; Washington, D. C. U.S.A. Food and Nutrition Bulletin 1981; 4:2.

[7] Eksmyr, R., Anthropometry in Privileged Ethiopian PreSchool children. CNU Report no. 33, Acta Pediat Scand. 1970; 59:159-163.

[8] Ethiopian Nutrition Institute 1989. News Letter Publications of the Ethiopia Nutrition Institute Ministry of Health.

[9] Dalit Community. (n.d.). Retrieved January 9, 2018 from http://en.banglapedia.org/index.php?title=Dalit_Community.

[10] Islam, M., Parvez, A., Dalit Initiatives in Bangladesh; 2013, pp 12.

[11] Rahman, K. F. 2016, January 19 The Dalits in Bangladesh. The Daily Star, Retrieved from http://www.thedailystar.net/law-our-rights/rightsadvocacy/the-dalits-bangladesh-203845.

[12] Dalit Children in Bangladesh, Committee on the Rights of the Child (CRC) 70th Session, 2015, Alternative NGO report by the International Dalit Solidarity Network (IDSN), pp 2.

[13] Kumari, V., Singh, A. 2017 Assessment of nutritional status of pre-school children of anganwadi of labour colony, H. A. U, International Journal of Science and Technology.; 6 (1); 591-597.

[14] Shah, S. K., Shetty, S,. K, Shingh, D. R,. Mathias, J., Upadhyay, A., Pandit, R. 2016 Prevalence of Undernutrition among Musahar Children Aged Between 12 To 59 Months in Urban Siraha District, Nepal, MOJ Public Health.; 4 (5): 00093.

[15] World Health Organization, "WHO Child Growth Standards. Length/Height-for-age, Weight-for-age, Weight-for-length, Weight-for-height and Body Mass Index-for-age: Methods and Development, "Geneva, 2006, pp. 306-307.

[16] World Health Organization,“Anthro for personal computers, Version 3.2.2. Software for assessing growth and development of the world's children," Geneva, Available at: http://www.who.int/childgrowth/software/en (accessed 17.01.2014), 2007.

[17] Bangladesh Demographic and Health Survey-2014 Mitra and Associates, and ICF International, Dhaka, Bangladesh, Cahpter 11- Nutrition of children and women, pp 151.

[18] IDSN briefing note· Bangladesh 2015 (Issue brief). (n.d.).

[19] Finlay, J. E., Ozaltin, E., Canning, D. 2011 The association of maternal age with infant mortality, child anthropometric failure, diarrhea and anaemia for first births: evidence from 55 low- and middle-income countries. BMJ Open; 1: e000226. 
[20] Unit For Sight. (n.d). Retrieved January 4, 2018, from http://www.uniteforsight. org/ nutri-tion/module5\#_ftn2.

[21] Sommerfelt, A. Elizabeth, S. Kathryn, “Children's nutritional status. DHS Comparative Studies" No. 12. Calverton, Maryland, USA: Macro International Inc., 1994.

[22] Tigga, P. L., Sen, J. 2016 Maternal Body Mass Index Is Strongly Associated with Children Z -Scores for Height and BMI, Journal of Anthropology; http://dx.doi.org/10.1155/2016/6538235.

[23] Arya, A., Devi, R. 1991 Influence of maternal literacy on the nutritional status of preschool children; Indian Journal of Pediatrics.; 31 (8): 265- 268.
[24] Roy, R. K., Matubbar, M. S., Kamruzzaman, M,. Asad UdDaula, A. 2015 Determination of Nutritional Status of UnderFive Year Children Employing Multiple Interrelated Contributing Factors in Southern Part of Bangladesh, International Journal of Nutrition and Food Sciences.; 4 (3): 264-272.

[25] Sarwar, M. T., Sultana, M. A., Akter, S., Rahman, M. S., Rouf, M. A., Raza, M. S., Hossain, M. S. 2015 A Study on the Nutritional Status of Preschool Children in Three Districts of Bangladesh, Science Journal of Public Health.; 3 (5): 633-637. 